PublisherName : BioMed Central

PublisherLocation : London

Publisherl mprintName : BioMed Central

\title{
Effects of molecular and functional intestinal adaptation to chronic LPS administration
}

\begin{tabular}{|c|c|c|}
\hline \multicolumn{3}{|c|}{ Articlel nfo } \\
\hline ArticlelD & : 1370 & \\
\hline ArticleDOI & : 10.1186/cc1329 & \\
\hline ArticleCitationID & : P265 & \\
\hline ArticleSequenceNumber & : 258 & \\
\hline ArticleCategory & : Meeting abstract & \\
\hline ArticleFirstPage & $: 1$ & \\
\hline ArticleLastPage & $: 2$ & \\
\hline \multirow[t]{3}{*}{ ArticleHistory } & : RegistrationDate & : 2001-1-15 \\
\hline & Received & : 2001-1-15 \\
\hline & OnlineDate & : 2001-3-2 \\
\hline ArticleCopyright & : The Author(s)2001 & \\
\hline ArticleGrants & : & \\
\hline ArticleContext & : 1305455S1S1 & \\
\hline
\end{tabular}

NT Schwarz, Aff1 Aff2

J C Kalff, Aff1 Aff2

TR Billiar,Aff1 Aff2

$\mathrm{RL}$ Simmons, Aff1 Aff2

A Hirner, Aff1 Aff2

AJ Bauer, Aff1 Aff2

Aff1 Department of Surgery, University of Bonn, D-53105 Bonn, Germany

Aff2 Department of Surgery and Department of Medicine, University of Pittsburgh, Pittsburgh, PA 15261, USA 


\section{Introduction}

We and others have shown that a single injection of LPS or IM alone triggers an acute molecular and cellular inflammatory response within the intestinal muscularis which results in ileus. We also have shown in unpublished data, that LPS potentiates the inhibitory effects of intestinal manipulation on the small intestine. It is known, that LPS induces adaptational processes. The objective of this study was to investigate the effect of molecular preconditioning of the intestine by continous LPS administration and its potential cross-adaptation towards other insults.

\section{Methods}

SD rats were treated daily with an i.p. injection of LPS ( 1 or $12.5 \mathrm{mg} / \mathrm{kg}$ ) for 1 or 7 consecutive days ( $n$ $=4, P<0.05$ ). Gentle intestinal manipulation (IM) was performed $24 \mathrm{~h}$ after the last LPS administration. J ejunal circular muscle strips were functionally evaluated using organ bath recordings $24 \mathrm{~h}$ after intestinal manipulation. MPO staining was assessed to measure the neutrophil recruitment into the muscularis. RTPCR and electrophoretic mobility shift assays (EMSAs) were performed on isolated jejunal muscularis extracts.

\section{Results}

EMSA for NF-KB, NF-IL-6 and STAT3 showed a 3.2-, 3.8-and 8.6-fold increase in activation in the jejunal muscularis $3 \mathrm{~h}$ after IM compared to controls. This transcriptional response demonstrated significant adaptation when doing the manipulation with the 7th consecutive administration with only a 3.1-, 4.0- and 3.0- fold activation of NF-KB, NF-IL-6 and STAT3 $3 \mathrm{~h}$ after manipulation following the 7th LPS injection. RTPCR showed an acute significant 6.0-fold upregulation in IL-6 mRNA within the muscularis $3 \mathrm{~h}$ after IM, which was significantly increased after a single LPS administration but adapted to a 3.8-fold increase at IM after 7 days of LPS pretreatment. Similar quantitative observations were also made for TNF-a and iNOS. Functionally, IM caused a significant suppression of in vitro contractility ( $24 \mathrm{~h}$ after IM $=0.53 \pm 0.047$ vs Control $=1.26 \pm 0.07 \mathrm{~g} / \mathrm{mm}^{2} / \mathrm{s}$ at $300 \mu \mathrm{M}$ bethanechol). However, chronically LPS injected animals had contractile responses similar to control $\left(1.28 \pm 0.02 \mathrm{~g} / \mathrm{mm}^{2} / \mathrm{s}\right.$, at $300 \mu \mathrm{M}$ bethanechol). IM following this LPS preconditioning didn't affect the bethanechol stimulated response compared to controls (1.02 \pm 0.08 $\mathrm{g} / \mathrm{mm}^{2} / \mathrm{s}$, at $300 \mu \mathrm{M}$ bethanechol).

\section{Conclusion}

We conclude that significant intestinal adaptation occurs in response to chronic LPS through a downregulation in the inflammatory milieu and a significant recovery in in vitro muscle contractility. 